\title{
Zirkonyum Destekli Sabit Protetik Restorasyonlarda Klinik Başarı Değerlendirme Kriterleri
}

\author{
Clinical Success Evaluation Criteria in Zirconia-Based FixedI Prosthesis \\ Elçin KESKIN ÖZYER ${ }^{1}$, Erkut KAHRAMANOĞLU²@, Şükrü Can AKMANSOYe, Yasemin KULAK ÖZKAN ${ }^{4}$
}

$\ddot{O} z$

Sabitprotetikrestorasyonlarda metal destekli seramik restorasyonlar klinik olarak uzun yıllardan beri başarıyla kullanılmalarına rağmen yapısındaki metal alt yapının; restorasyonun 1şık geçirgenliğini azaltarak estetik sakıncalara yol açması, özellikle marjinlerde metal-iyon renklenmesi ile gri renkte hoş olmayan bir görüntüye sahip olmas1, lokal doku reaksiyonuna ve korozyon toksisitesine sebep olabilmesi gibi dezavantajlarından ötürü bu materyal yerine yeni arayışların doğmasını gerektirmiştir.

Günümüzde çok sayıda güçlendirilmiş tam seramik sistemi geliştirilmiştir. Güçlendirilmiş tam seramik sistemleri arasında zirkonyum esaslı seramik restorasyonlar, yüksek dayanıklılık ve estetik özelliklerinden dolayı tercih edilirler. Klinikte zirkonyum oksitin kor materyali olarak kullanımı tatminkar optik özellikler, 1000 MPa’1 geçen yüksek bükülme direnci, biyolojik uyumluluğu ve translüsent olması gibi avantajları sayesınde tercih edilmektedir. Bunlardan en yaygın olarak kullanılanı yttrium ile stabilize edilmiş zirkonyum oksit polikristalleridir.

Kullanılan materyallerin ve uygulama tekniklerinin başarılarını ve özelliklerini belirleyebilmek, restorasyonların klinik prognozunu belirlemek, restorasyonları oral çevrede değerlendirebilmek amacıyla kontrollü klinik çalışmalara ihtiyaç vardır. Bu nedenle bir takım klinik başarı değerlendirme kriterleri

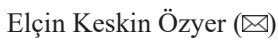

${ }^{1}$ Marmara University Faculty of Dentistry, Prosthodontics Department, Istanbul/TURKEY Tel: 021642116 21, Fax: 02164210291

e-mail:elcinozyer@marun.edu.tr

Erkut Kahramanoğlu

${ }^{2}$ Doktor Öğretim Üyesi, Marmara Üniversitesi Diş Hekimliği Fakültesi, Protetik Diş Tedavisi Anablim Dalı İstanbul, Türkiye

Şükrü Can Akmansoy

${ }^{3}$ Araştırma Görevlisi, Marmara Üniversitesi Diş Hekimliği Fakültesi, Protetik Diş Tedavisi Anablim Dalı İstanbul, Türkiye

Yasemin Kulak Özkan

${ }^{4}$ Profesör Doktor, Marmara Üniversitesi Diş Hekimliği Fakültesi, Protetik Diş Tedavisi Anablim Dalı İstanbul, Türkiye

Submitted / Gönderilme: 14.09.2018

Accepted/Kabul: 22.03.2019 oluşturularak standardizasyona bağlanmıştır. Belli standartlar ölçütünde restorasyonun klinik olarak değerlendirilmesi ve başarısına karar verilmesi mümkündür.

Anahtar Kelimeler: Zirkonyum, Estetik, Klinik Başarı.

\section{Abstract}

Although metal-supported ceramic restorations have been clinically used for many years with success in fixed prosthetic restorations, there is a need for an alternative because metal infrastructures decrease light transmittance, resulting in aesthetic drawbacks. They have a grey colour due to metal-ion colouring, especially in the margins, and they might cause local tissue reaction and corrosion toxicity.

Currently, several strengthened all-ceramic systems have been developed. Zirconia-based ceramic restorations are among the preferred strengthened all-ceramic systems due to their high durability and aesthetic characteristics. The use of zirconium oxide as a core material is also clinically preferred due to its advantages such as satisfactory optical properties, bending resistance of over $1000 \mathrm{MPa}$, biological compatibility and translucency. The most commonly used ones are yttria-stabilised zirconia polycrystals.

In order to assess the success and characteristics of used materials and application methods, controlled clinical studies are needed to determine the clinical prognosis of restorations and evaluate restorations in the oral environment. Thus, several clinical success evaluation criteria were created and standardised. It is possible to clinically evaluate restorations and determine their success according to certain standards.

Keywords: Zirconium, Aesthetics, Clinical Success.

\section{ZİRKONYUM}

\section{Zirkonyumun Kimyasal ve Fiziksel Özellikleri}

Zirkonyum ilk olarak 1789 yılında Alman kimyacı Martin Heinrich Klaproth tarafından, birtakım değerli taşların 1sıtılması sonucu reaksiyon ürünü olarak bulunmuştur (Piconi C ve Macauro G, 1999). Sembolü ' $Z r$ ' olan zirkonyum, atom numarası 40 ve atom kütlesi 91,22 olan; 
periyodik cetvelin 5 . periyodunda $4 \mathrm{~b}$ grubunda yer alan geçiş metal elementidir (Vagkopoulou T ve ark, 2009).

Zirkonyum elementi, oda sıcaklığında heksagonal sıkı paketlenmiş kristalin yapıda olup doğada saf halde bulunmaz; birçok farklı bileşik halinde bulunabilir. Bunlar zirkonat ( $\mathrm{ZrO3})$, zirkonil tuzu $(\mathrm{ZrO}+2)$ ve en önemli birleşiği olan zirkonyum oksittir (ZrO2) (Akkayan B ve Gülmez T, 2002).

Reaktif bir element olan zirkonyum, hava veya siv1 ile temas ettiğinde yüzeyinde oksit tabakası oluşur ve bu sayede zirkonyumun korozyona karşı daha dirençli olması sağlanır (Denry I ve Kelly JR, 2008). Sertliği, aşınma direnci, dayanıklılığı, yüksek korozyon direnci ve ani 1sısal değişimlere dayanıklılığı gibi özellikleri nedeni ile endüstride kullanım alanı bulan zirkonyum, ortopedide ilk olarak 1960'lı y1llarda biyomateryal olarak kullanılmaya başlanmıştır. Diş hekimliğinde ise, ortodontik braketlerde, post-kor sistemlerde, implant dayanaklarında ve implantlarda kullanılmaktadır.(Piconi C ve Macauro G, 1999) (Vagkopoulou T ve ark, 2009) (Tablo 1).

Tablo 1. Zirkonyumun fiziksel özellikleri

\begin{tabular}{ll}
\hline Yoğunluğu & $6.511 \mathrm{~g} / \mathrm{ml}$ \\
\hline Elastik modülü & $8.3 \times 104 \mathrm{MPa}$ \\
Erime noktası & $1855^{\circ} \mathrm{C}(2128 \mathrm{~K})$ \\
Kaynama noktası & $4409^{\circ} \mathrm{C}(4682 \mathrm{~K})$ \\
Molar hacmi & $14.02 \mathrm{ml} / \mathrm{mol}$ \\
Mineral Sertliği & 5.0 \\
Isı iletkenliği & $0.227 \mathrm{~W} \mathrm{~cm}^{-1} \mathrm{~K}^{-1}$ \\
Özgül 1sı & $0.27 \mathrm{~J} \mathrm{~kg}^{-1} \mathrm{~K}^{-1}$ \\
\hline
\end{tabular}

\section{Zirkonyumun Yapısal Özellikleri}

Saf zirkonyumun kaynama sicaklı̆g $4409{ }^{\circ} \mathrm{C}$ olup, erime sıcaklığ $1855^{\circ} \mathrm{C}$ 'dir ve düşük termal etkinliğe sahiptir (Piconi ve Maccauro, 1999). Zirkonyum oksit $\left(\mathrm{ZrO}_{2}\right)$ polimorfik bir malzemedir. Kristalin ağ1 içinde yer alan zirkonyum oksit kristalleri, 3 farklı kristal faz yapısına göre sınıflandırılır: monoklinik, tetragonal ve kübik fazlardır. Saf zirkonyum 1170 ${ }^{\circ} \mathrm{C}$ 'ye kadar olan oda 1sisında monoklinik fazda stabildir. Bu fazda zirkonyumun mekanik özellikleri düşüktür ve seramik partiküllerinin kohezyonunun azalması ve buna bağlı olarak yoğunluğun azalması kolaylaşabilir. $1170^{\circ} \mathrm{C}$ ile $2370^{\circ} \mathrm{C}$ arasında zirkonyum, hacim olarak \% 5 azalma göstererek tetragonal fazda stabil hale geçmiştir ve materyalin mekanik özellikleri gelişmiştir. Sicaklı̆ğın artmasıyla beraber $2370{ }^{\circ} \mathrm{C}$ 'nin üzerinde materyal kübik faza dönüşmektedir ve erime sıcaklığına kadar $\left(2680^{\circ} \mathrm{C}\right.$ ) stabildir (Şekil 1) (Denry I ve Kelly JR, 2008) (Piconi C ve Macauro G, 1999) (Vagkopoulou T ve ark, 2009).

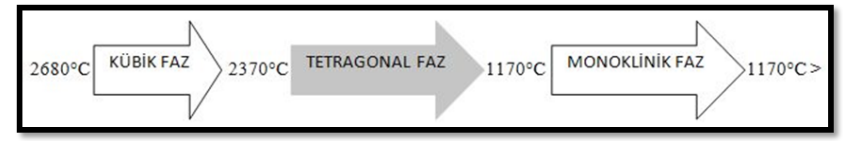

Şekil 1. Zirkonyumun kristal fazları ve dönüşüm sıcaklıkları.

Zirkonyum dioksit firınlama 1sisinda tetragonal, oda sıcaklığında ise monoklinik fazdadır (Kelly, 2004).

\section{Transformasyon Doygunluğu (PTT)}

Her ne kadar oda sıcaklığında tetragonal fazda stabilize edilse de zirkonyum 'metastable' özelliğe sahiptir yani tetragonal fazdan monoklinik faza dönüşümü sağlayacak enerji mevcuttur; aşındırma gibi yüksek lokalize stresler altında, kumlamada (Curtis AR ve ark, 2006) ve isıl yaşlandırmada monoklinik faza dönüşüm gerçekleşebilir (Lughi V ve Sergo V, 2010). $\mathrm{Bu}$ dönüşüm \% 3-4 arasında lokal hacim artışı ile sonuçlanır. Kristaller etkili bir şekilde büyüyüp bu hacim artışı ile çatlağın çevresinde kompresif stresler oluşturur ve bu stresler sayesinde mikroçatlakların ilerlemesi engellenir. İşte bu tetragonal fazdan monoklinik faza dönüşüme, 'tranformasyon doygunluğu' (phase transformation toughening, PTT) denir (Silva N ve ark, 2010). Ancak, yapılan çalışmalarda bu mekanizmanın mikro çatlakların oluşmasını ve ilerlemesini engellemediği sadece mikro çatlakların yayılmasını zorlaştırdığı belirtilmiştir (Raigrodski AJ, 2004). Lughi V ve Sergo V, transformasyon doygunluğunu materyalin bir çatlak mevcudiyetinde gelen yüklere karşı koyabilme kapasitesi olarak tanımlamışlardır (Lughi V ve Sergo V, 2010).

\section{Düşük Isılarda Bozulma (LTD)}

'Düşük 1sılarda bozulma' (low temperature degradation) fenomeni, zirkonyumun kendi yapısında var olan ve düşük 1sılarda $\left(150-400{ }^{\circ} \mathrm{C}\right)$ özellikle suyun varlığında zirkonyum kristallerinin spontan olarak tetragonal fazdan daha zayıf olan monoklinik faza geçmesi ile yapısının fiziksel özelliklerini zayıflatmasına sebep olan bir durumdur (AlAmleh B ve ark, 2010). Tetragonal fazdan $\rightarrow$ monoklinik faza dönüşümü 'transformasyon doygunluğu' mekanizmasina yol açmasının yanında materyalin faz bütünlüğünü tehlikeye atıp 'düşük ssılarda bozulma' (low temperature degradation) fenomenine yatkınlığını da arttırmaktadır (Silva N ve ark, 2010). Bunun sonucunda Y-TZP partiküllerinin yüzeyden atması ve mikroçatlak oluşumu ile erken dönemde başarısızlıklara neden olabilmektedir (Silva N ve ark, 2010). 


\section{Zirkonyum Materyalleri}

Dental uygulamalar için üretilmiş stabilize edici ajan tipi bakımından 4 farklı zirkonyum materyali bulunmaktadır:

- Parsiyel stabilize zirkonyum (PSZ),

- Zirkonyum ile sertleştirilmiş alumina (ZTA),

- Alumina ile sertleştirilmiş zirkonyum (ATZ) ve

- Yttrium ilave edilmiş tetragonal zirkonyum polikristali (3Y-TZP) (Silva N ve ark, 2010).

Yttrium oksitin (Y2O3) diğer metal oksitlerden daha üstün özelliklere sahip olması nedeniyle genelde stabilize edici ajan olarak yttrium kullanılır (Piconi C ve Maccauro G, 1999).

Yttrium Stabilize Tetragonal Zirkonyum Polikristali (Y-TZP)

Yttrium oksitin $\left(\mathrm{Y}_{2} \mathrm{O}_{3}\right)$, saf zirkonyuma \% 2-3 mol oranında ilave edilmesiyle elde edilen yttrium stabilize tetragonal zirkonyum polikristali (Y-TZP), en güçlü ve en çok kullanılan zirkonyum çeşididir. Y-TZP seramikleri, $\mathrm{ZrO}_{2}$ ile $\mathrm{Y}_{2} \mathrm{O}_{3}$ 'ün beraber çöktürülmesi yoluyla veya $\mathrm{ZrO}_{2}$ grenlerinin $\mathrm{Y}_{2} \mathrm{O}_{3}$ ile kaplanması yoluyla elde edilebilir (Piconi C ve Maccauro G, 1999).

Y-TZP materyali, yüksek dayanım, kırılma tokluğu, sertlik, aşınmaya karşı direnç, biyouyumluluk, manyetik içermeyen davranış, elektrik yalıtımı, düşük termal iletkenlik, asit ve alkali içinde korozyona direnç, çeliğe benzer elastiklik modülü ve demire benzer termal ekspansiyon katsayısı gibi özelliklere sahiptir (Vagkopoulou T ve ark, 2009).

Y-TZP esaslı altyapı sistemlerinin bükülme dirençleri 900-1200 MPa arasındadır. Kırılma dayanımları ise alüminöz altyapı sistemlerinin yaklaşık 2 katı, lityum disilikat içeren sistemlerin ise yaklaşık 3 katı kadardır (Tablo 2) (Piconi C ve Maccauro G, 1999).

Tablo 2. Y-TZP' nin yapısal özellikleri

\begin{tabular}{ll}
\hline Özellik & Y-TZP \\
\hline Kimyasal kompozisyon & $\mathrm{ZrO}_{2}+3 \mathrm{~mol}^{2} \mathrm{Y}_{2} \mathrm{O}_{3}$ \\
Yoğunluk & $>6 \mathrm{~g} / \mathrm{cm}^{3}$ \\
\hline Porözite & $<0.1 \%$ \\
Bükülme direnci & $900-1200 \mathrm{MPa}$ \\
Baskı dayanımı & $2000 \mathrm{MPa}$ \\
Young modülus & $210 \mathrm{GPa}$ \\
Kırılma dayanımı & $7-10 \mathrm{MPa} \mathrm{m} \frac{1}{2}$ \\
Isısal genleşme katsayısı & $11 \times 10^{-6} \mathrm{~K}^{-1}$ \\
\hline Termal iletkenlik & $2 \mathrm{~W} \mathrm{~m} \mathrm{~K}{ }^{-1}$ \\
Sertlik & $1200 \mathrm{HV}$ \\
\hline
\end{tabular}

\section{Y-TZP Seramik Restorasyonların Endikasyonları}

1. Anterior ve posterior bölge tek kronlar,

2. Üç-dört üniteli köprüler (Raigrodski AJ, 2004) (Raigrodski AJ ve Chiche GJ, 2001). Y-TZP Seramik Restorasyonların Kontrendikasyonlart

1. Örtülü kapanış vakalarında,

2. Yetersiz oklüzal mesafe,

3. Yetersiz destek diş kron boyu,

4. Bruksizm gibi parafonksiyonel alışkanlıklar,

5. Kanatlı köprü (kantilever) kullanımı tasarlandığında,

6. Yetersiz periodontal destek (Raigrodski AJ, 2004) (Raigrodski AJ ve Chiche GJ, 2001). $\underline{\text { Y-TZP Seramik Restorasyonlarm Avantajlart }}$

1. Yüksek dayanıklılık, kırılma sertliği gibi üstün mekanik özelliklere sahiptir,

2. Biyouyumludur, lokal veya sistemik yan etkiler görülmez,

3. İnce partiküllü yapısı sayesinde detaylı şekillendirilebilmektedir,

4. Preparasyon dişeti hizasında veya üzerinde bitirilebilmektedir,

5. Isısal iletkenliğin düşük olması hassasiyet ve pulpa irritasyonlarını önlemektedir,

6. Titanyuma göre daha az bakteri birikimi görülmektedir,

7. Radyopak olduğu için restorasyonun radyolojik değerlendirmesine olanak sağlamaktadır,

8. Simantasyonu için adeziv yapıştırma önerilmekle beraber konvansiyonel teknikler de kullanılabilmektedir (Raigrodski AJ, 2004) (Rimondini L ve ark, 2002).

\section{Y-TZP Seramik Restorasyonların Dezavantajlart}

1. Görünümleri opaktır,

2. Aşındırma ve yüzey işlemlerinin, materyalin mekanik özellikleri üzerinde olumsuz etkileri vardır,

3. Köprü protezlerinde, interoklüzal mesafenin yetersiz olduğu vakalarda gövde ile destek kronun birleşim alanı daralacağından oklüzal kuvvetler altında restorasyonun dayanıklılığı azalmaktadır,

4. Bu restorasyonlarda uyumsuzluk görüldüğünde yeni bir ölçü alınarak tekrar yapılmaları gerekir (Raigrodski AJ, 2004) (Rimondini L ve ark, 2002). 


\section{MONOLITIKK ZİRKONYA}

Monolitik terimi Yunanca'daki "mono: tek" ve "lithos: taş" kelimelerinden gelmektedir. Malzemelerin baştanbaşa düzenli bir özelliğe sahip olduğu anlamına gelir.

Zirkonyum seramikler opak beyaz renkte oldukları için feldspatik porselenlerle veneere edilerek, alt yapı materyali olarak kullanılmıştır (Zhang Y ve ark, 2013). Bu kronlarda karşılaştığımız en büyük problem ve kısa ömürlü olma sebepleri özellikle veneer porselen ile zirkonyum alt yap1 arasında meydana gelen "chipping" denilen kopma ve kohesiv kırılmalardır (Triwatana ve ark, 2012). Bunun için $\mathrm{CAD} / \mathrm{CAM}$ sistemlerle üretilen, veneer porselene ihtiyaç duyulmayan, yalnızca tek bir materyalden üretilen monolitik kronlargeliştirilmiştir. Sonzamanlarda, monolitikzirkonyum restorasyonlar yüksek mekanik özellikleri, antagonist dişte düşük aşınma ve yüksek estetik özeliklerinden dolayı ilgi odağ varlığında da implant üstü monolitik zirkonyum restorasyon kullanılması yaygınlaşmaktadır (Marchack ve ark, 2011).

MZ' ler yüksek biyouyumluluğa sahip oldukları gibi; gözeneksiz yapısı ve yüksek translüsenslik özellikleri sayesinde mükemmel doğal görünüme sahiptirler. Görünümlerinin bu derece doğala yakın olması sebebi ile estetiği sağlamak için seramiklerle veneere edilmeleri gerekmemektedir. Yalnızca özel boyama solüsyonları ile boyanarak doğal diş rengi elde edilebilmektedir. (Batson ER ve ark, 2014).

Monolitik zirkonyumlar, kısmi olarak ytrium ile stabilize edilmiştir (\%0.01). Bu da materyale; yüksek bükülme direnci (1570 MPa) ve yüksek 1sıya dayanma gücü $\left(2600^{\circ} \mathrm{C}\right.$ 'ye kadar) vermektedir. Özellikle 1sıya karşı olan bu direnç, yüksek boyutsal stabiliteye sahip bir materyal olmasını sağlamaktadır (Zhang Y ve ark, 2013). Solid ya da translusent olarak da adlandırılan bu blokların yapısındaki atomlar, herhangi bir organik bağlayıcı olmadan birbirinin içine geçmektedir.

Ayrıca aşınma dirençleri doğal dişe çok yakındır. Veneer seramik olarak kullanılan porselenin mikroyapısı, zamanla karşı1 doğal dişte abrazyonlara ve yaşlanmalara sebep olurken; MZ kron böyle bir abrazyon dezavantajına sahip değildir (Batson ER ve ark, 2014).

\section{MZ Seramik Restorasyonların Endikasyonlarl}

Zirkonyum alt yapılı seramik kronların kullanıldığ 1 tüm endikasyonlar, monolitik zirkonyum için de geçerlidir. Ayrıca yüksek sertlik ve kırılma dirençlerinden dolayı;
1. Uzun gövdeli köprü protezlerinde

2. Full ark köprü protezlerinde

3. İnterokluzal mesafenin yetersiz olduğu durumlarda

4. Endokronlarda

5. İnley ve onley kronlarda

6. İmplantüstü kronlarda kullanım alanı bulmaktadır.

MZ Seramik Restorasyonlarin Avantajlarl

1. Daha yüksek translüsenslik

2. Seramik-zirkonyum arasında kopma olmaması

3. Antagonist dişte abrazyona sebep olmaması

4. Daha yüksek bükülme direnci

5. Dişlerde minimal preparasyon gerektirmesi olarak sayılabilir (Zhang Y ve ark, 2013).

MZ Seramik Restorasyonların Dezavantajları

1. Maliyet

2. Laboratuvar aşamalarının zor olmasıolarak gösterilebilir.

\section{KLİNIKK DEĞERLENDİRME VE BAŞARI KRİTERLERİ}

1960’lı yllarda klinik takip ve uygulama yöntemleri araştırılmaya başlanmıştır ve standardize edebilmek için Cvar ve Ryge, 1971 yllında restorasyonların klinik başarısının değerlendirilmesinde United States Public Health Service (USPHS) kriterlerini geliştirmişlerdir (Randall RC ve Wilson NHF, 1999). Restorasyonların klinik değerlendirmelerinde restorasyonların komşu diş ve/veya restorasyonlarla olan renk uyumlarına, restorasyonların bitim sinırlarında renklenmenin olup olmadığına, restorasyonların anatomik formlarının devamlılı̆̆ına, bitim sınırındaki adaptasyonlarına ve sekonder çürük olup olmadığına göre değerlendirmeleri yapılır. Tüm bu veriler sonucunda klinik olarak kabul edilebilir olup olmadığına karar verilir. Restorasyonların klinik olarak uygun olma durumu iki ayrı grupta değerlendirilir; ideal restorasyonlar Alfa olarak adlandırılırken, kabul edilebilir restorasyonlar Bravo olarak belirtilir. Klinik olarak uygun olmayanlar ise, restorasyonun çevre dokulara zarar verme durumunda kısa süre de değiştirilmesi gereken restorasyonlar Charlie, hemen değiştirilmesi gereken restorasyonlar Delta olarak belirtilir (Monaco C ve ark, 2006) (Sailer I ve ark, 2013).

USPHS sistemi, restorasyonların kalitesi değerlendirilirken başarının derecesinden çok, restorasyonun kabul edilebilirliğini belirleyecek şekilde hazırlanmıştır. Anatomik form, marjinal 
adaptasyon ve marjinal renklenme gibi değerlendirme kriterlerinde meydana gelen küçük değişiklikleri belirlemede yeterli hassasiyete sahip değildir. Bu amaçla Modifiye USPHS yada Ryge kriterleri olarak adlandırılan klinik değerlendirme kriterleri kullanılmaya başlanmıştır (Tablo 3).

Tablo 3. Modifiye USPHS-Ryge klinik değerlendirme kriterleri

\begin{tabular}{|c|c|c|c|}
\hline Kategori & $(+)$ & $(-)$ & Direkt Klinik Degerlendirme Kriterleri \\
\hline \multirow{4}{*}{$\begin{array}{l}\text { Anatomik } \\
\text { Form }\end{array}$} & 0 & & Restorasyon formu anatomiyi takip ediyor. \\
\hline & 1 & & $\begin{array}{l}\text { Hafifçe az veya fazla konturlu restorasyon; } \\
\text { marjinal ridgeler hafifçe az konturlu; kontak } \\
\text { hafif açı; okluzal yükseklik lokal olarak azdır. }\end{array}$ \\
\hline & & 2 & $\begin{array}{l}\text { Restorasyon underkonturlu, dentin açıkta, } \\
\text { kontak hatalı, okluzal yükseklik azalmış, } \\
\text { oklüzyon etkilenmiş durumdadır. }\end{array}$ \\
\hline & & 3 & $\begin{array}{l}\text { Restorasyonda eksik var veya travmatik } \\
\text { okluzyon var, restorasyon dişte veya komşu } \\
\text { dişte ağriya neden oluyor. }\end{array}$ \\
\hline \multirow[t]{5}{*}{$\begin{array}{l}\text { Marjinal } \\
\text { adaptasyon }\end{array}$} & 0 & & $\begin{array}{l}\text { Restorasyon marjinleri takip ediyor, sond } \\
\text { takılmiyor. }\end{array}$ \\
\hline & 1 & & Sond takılıyor ama çatlak yoktur. \\
\hline & 2 & & Marjinde çatlak var, mine açıktadır. \\
\hline & & 3 & Ciddi çatlak var, dentin açıktadır. \\
\hline & & 4 & Restorasyon hareketli, çatlak veya uzaklaşmış \\
\hline \multirow[t]{5}{*}{ Renk uyumu } & 0 & & İyi renk uyumu, restorasyon fark edilemiyor. \\
\hline & 1 & & İyi renk uyumu vardır. \\
\hline & 2 & & Hafif uyumsuzluk vardır. \\
\hline & & 3 & Orta derecede uyumsuzluk vardır. \\
\hline & & 4 & Çok fazla uyumsuzluk vardır. \\
\hline \multirow{4}{*}{$\begin{array}{l}\text { Marjinal } \\
\text { renklenme }\end{array}$} & 0 & & Renklenme yok. \\
\hline & 1 & & Hafif renklenme, cilalama ile uzaklaşabilir. \\
\hline & 2 & & Belirgin renklenme, cilalama ile uzaklaşmıyor. \\
\hline & & 3 & Çok fazla renklenme var. \\
\hline $\begin{array}{l}\text { Sekonder } \\
\text { çürük }\end{array}$ & 0 & 1 & $\begin{array}{l}\text { Çürük belirtisi yok. } \\
\text { Çürük belirtisi var. }\end{array}$ \\
\hline \multirow{4}{*}{$\begin{array}{l}\text { Yüzey } \\
\text { pürüzlülüğü }\end{array}$} & 0 & & Pürüzsüz yüzey mevcuttur. \\
\hline & 1 & & Hafif pürüzlü, oyuklu yüzey mevcuttur. \\
\hline & 2 & & Pürüzlü yüzey, düzeltilemiyor. \\
\hline & & 3 & Derin oyuklu yüzey mevcuttur. \\
\hline \multirow{2}{*}{$\begin{array}{l}\text { Diş } \\
\text { bütünlüğü }\end{array}$} & 0 & & Dişte kırılma yok. \\
\hline & & 1 & Dişte kırılma var. \\
\hline \multirow{2}{*}{$\begin{array}{l}\text { Restorasyon } \\
\text { bütünlüğü }\end{array}$} & 0 & & Restorasyonda kırılma yok. \\
\hline & & 1 & Restorasyonda kırılma var. \\
\hline \multirow{2}{*}{$\begin{array}{l}\text { Postoperatif } \\
\text { hassasiyet }\end{array}$} & 0 & & Hassasiyet yok. \\
\hline & & 1 & Hassasiyet var. \\
\hline \multirow[t]{3}{*}{ Retansiyon } & 0 & & Restorasyon ağızda durmaktadır. \\
\hline & 1 & & Restorasyonun bir kısmı düşmüştür. \\
\hline & & 2 & Restorasyonun tamamı düşmüştür. \\
\hline
\end{tabular}

Modifiye USPHS ile değerlendirmelere kronların kontakları, dişlerde simantasyon sonrası oluşabilecek postoperatif hassasiyette katılmıştır (Bindl A ve Mörmann WH, 2002).
Klinik değerlendirmelerde sıklıkla kullanılan bir diğer sistemde 1973 yılında California Dental Association'in (CDA) (Tablo 4) geliştirdiği sistemdir. Bu sistem iki bölüme ayrılmış olup 'klinik olarak kabul edilebilir' restorasyonlar yada 'klinik olarak kabul edilemez' restorasyonlar olarak belirtilirler. Her iki temel grupta ikişer alt grup içerir (Poggio CE ve ark, 2012) (Beier US ve ark, 2012). Böylece hekimin, ağızdaki mevcut restorasyonları değerlendirmesi sağlanmış olur.

Tablo 4. CDA klinik değerlendirme kriterleri

\begin{tabular}{ll}
\hline Değerlendirme & KLINIK OLARAK KABUL EDÍLEBİLIR \\
\hline Romeo (R) & $\begin{array}{l}\text { Klinik kalite ve profesyonel performans } \\
\text { mükemmeldir. }\end{array}$ \\
Sierra (S) & Klinik kalite kabul edilebilir. \\
Değerlendirme KLINIKK OLARAK KABUL EDİLEMEZ \\
Tango (T) & $\begin{array}{l}\text { Restorasyonun tekrarlanması, değiştirilmesi ya da } \\
\text { düzeltilmesi gerekmekte, ileriki dönemde hastanın } \\
\text { dental sağlığına ve çiğneme sistemine zararlı etkileri } \\
\text { olabilir. }\end{array}$ \\
& $\begin{array}{l}\text { Restorasyonun derhal değiştirilmesi gerek, çünkü } \\
\text { hasar vermeye başlamış yada ciddi yetersizlikler } \\
\text { mevcuttur. }\end{array}$ \\
\hline
\end{tabular}

Victor, mümkün olan en kısa sürede restorasyonun değiştirilmesi gerektiğini ifade eder. Tango değeri, koruyucu sebeplerle restorasyonun yakın bir dönemde değiştirilmesi ya da yetersizliklerin tedavi edilmesi gerektiğini belirtir; Sierra değeri ideal şartlardan sapmalar bulunduğu ve dikkatli olunması gerektiğini belirtir. Bu sistem kullanılarak, bir restorasyon için 3 ayrı değer elde edilir; yüzey ve renk, anatomik form ve marjinal bütünlük (Anusavice KJ, 1989).

2007 yılında restorasyonların değerlendirilmesinde kullanılan yeni klinik kriterler içeren FDI Kriterleri, Journal of Adhesive Dentistry, Clinical Oral Investigations ve International Dental Journal olmak üzere 3 farklı dergide yayımlanmıştır. 2007 yılında FDI World Dental Federation'ın bilimsel komitesi tarafindan kriterler ve sınıflama olarak onay almıştır ve 2008 yılında klinik araştırma olarak restoratif materyal veya operatif tekniklerin değerlendirilmesinde standart kriterler olarak kabul görmüştür (Hickel $\mathrm{R}$ ve ark, 2010). FDI kriterlerinde restorasyonlar estetik, fonksiyonel ve biyolojik olmak üzere üç farklı kategoride değerlendirilmektedir (Hickel R ve ark, 2010). Estetik olarak yüzey parlaklığı,renklenmesi, renk uyumu ve translusensi, anatomik formu değerlendirilmektedir. Fonksiyonel olarak retansiyon ve materyal kırığı, marjinal adaptasyon, okluzal kontur ve aşınma, aproksimal anatomik form, radyografik değerlendirme, hastanın görüşü değerlendirilmektedir. Biyolojik olarak ise postoperatif 
hassasiyet ve vitalite, çürük tekrarı - erozyon - abfraksiyon, diş bütünlügü̈, komşu mukoza, oral ve genel sağlık durumu olarak değerlendirilmeltedir. Değerlendirme başlıkları klinik olarak çok iyi, klinik olarak iyi (düzeltme sonrası çok iyi) tedavi ihtiyacı yok, klinik olarak yeterli (minör aşınma; dişe zarar veren ve kabul edilemeyen bir sonuç yok), klinik olarak yetersiz (tamir edilebilir), klinik olarak başarısız (yenileme gerekli) şeklinde notlandırılmaktadır.

Modifiye USPHS kriterleri USPHS ve CDA klinik değerlendirme kriterlerine göre daha fazla detaylandırılmış olup klinik değerlendirmede diğer iki seçeneğe üstünlük sağlamaktadır. 2007 yılında kullanılmaya başlanan FDI kriterleri ile karşılaştırıldığında ise 2010 yılından 2016 yılına kadar yayınlanmış çalışmalarda kullanım yüzdesi \% 50'ye ulaşmış olan FDI kriterlerinin kullanımında önemli bir artış olduğu gözlenmiştir (Marquillier ve ark, 2017). FDI kriterlerinin restorasyonların kalitesindeki potansiyel farklılıkları ayırt etmede daha hassas olduğu (Coelho-DeSouza ve ark, 2012) bildirilmesine rağmen modifiye USPHS kriterleri ile karşılaştırıldığı çalışmlarda FDI kriterleri daha az güvenilir bulunmuştur (Frese C ve ark, 2013) (Staehle HJ ve ark, 2015).

Restorasyonların devamlılığı yumuşak doku sağlığı ile yakından ilişkilidir. Restorasyonların periodontal dokulara etkisini inceleyen klinik araştırmalar, zayıf marjinal adaptasyonun, dişeti altına uzanan derin marjin yerleşiminin, pürüzlü restorasyon yüzeylerinin ve taşkın konturlü restorasyonların lokalize periodontal enflamasyona yol açtığı bildirilmiştir. Periodontal değerlendirmeler ilk olarak restorasyonun uygulanmasından yaklaşık 1 ay sonra, sondla derinlik ölçümü, alveolarkemik seviyesinin radyografik olarak belirlenmesi ve gingival indeks değerlerinin elde edilmesi şeklinde gerçekleştirilir (Knoernschild KL ve Campbell SD, 2000). Restorasyonun etrafindaki enflamasyonu belirlemede sıklıkla Löe ve Silness Plak İndeksi (Tablo 5) ve Gingival İndeks (Tablo 6) Skalası kullanılır.

Gingival indeks skorları sayısal olmayan verilerdir; indeks skorundaki artış enflamasyon miktarında artış olduğunu ifade eder. Her bir hastanın kontralateral dişi "kontrol dişi" kabul edilerek aynı ölçümler bu diş için de gerçekleştilir. Her bir dişi çevreleyen doku 4 gingival üniteye bölünür: distofasiyal papilla, fasiyal marjin, mesiofasiyal papilla ve tüm lingual gingival marjin. Gingival indeks değerleri hastaların kontrol seanslarında artma gösteriyorsa bu dişetinde enflamasyon olarak yorumlanabilir (Carranza FA, 1996). Restore edilen diş ve kontrol dişi için elde edilen ortalama ve standart sapma değerleri belirlenir, uygun istatistiksel analizler yapılarak gruplar arasındaki farklılıklar belirlenir (Knoernschild KL ve Campbell SD, 2000).

Tablo 5. Löe ve Silness plak indeksi kriterleri

\begin{tabular}{|c|c|}
\hline Plak İndeks & \\
\hline Skor 0 & Dişeti bölgesinde plak yok. \\
\hline Skor 1 & $\begin{array}{l}\text { Serbest dişeti kenarında veya aynı bölgedeki diş } \\
\text { yüzeyinde sadece sondalama ile gözlenen plak birikimi } \\
\text { var. }\end{array}$ \\
\hline Skor 2 & $\begin{array}{l}\text { Dişeti cebinde, dişeti kenarında ve/veya aynı bölgedeki } \\
\text { diş yüzeyinde çılak göz ile görülebilir plak birikimi } \\
\text { var. }\end{array}$ \\
\hline Skor 3 & $\begin{array}{l}\text { Dişeti cebinde ve/veya dişeti kenarında ve aynı } \\
\text { bölgedeki diş yüzeyinde yumuşak madde birikimi var. }\end{array}$ \\
\hline
\end{tabular}

Tablo 6. Löe ve Silness gingival indeksi kriterleri

\begin{tabular}{ll}
\hline Gingival İndeks & \\
\hline Skor $\mathbf{0}$ & Sağlıklı doku \\
Skor $\mathbf{1}$ & $\begin{array}{l}\text { Hafif iltihap, hafif renk değişimi, hafif ödem, sond } \\
\text { ile } \\
\text { kanama yok }\end{array}$ \\
Skor 2 & $\begin{array}{l}\text { Orta derecede iltihap, kızarıklık, ödem ve parlaklık, } \\
\text { sond ile kanama var }\end{array}$ \\
Skor 3 & $\begin{array}{l}\text { İleri derece iltihap, belirgin kızarıklık ve ödem, } \\
\text { ülserasyon, spontan kanama }\end{array}$ \\
\hline
\end{tabular}

Klinik çalışmalarda hastalara uygulanan restorasyonlarla ilgili memnuniyetlerini ölçmek amaçlı memnuniyet anketleri uygulanabilir. Bu anketlerde hastaya sorular ile renk, yüzey pürüzlülüğü, çiğneme etkinliği, rahatlık, ağrı değerlendirmelerini yapmaları istenebilir. Ayrica hastalara genel olarak restorasyonlara 10 'u en yüksek kabul ederk 1'den 10'a kadar not vermeleri istenir. Tablo 7'de hasta memnuniyet anketi örneği gösterilmiş̧tir.

Tablo 7. Hasta Memnuniyeti Anketi

\begin{tabular}{|c|c|c|}
\hline & SKOR & DEĞERLENDİRME \\
\hline \multirow[t]{4}{*}{ RENK } & 1 & Çok iyi \\
\hline & 2 & İyi \\
\hline & 3 & Yeterli \\
\hline & 4 & Kötü \\
\hline \multirow[t]{4}{*}{ YÜZEY PÜRÜZLÜLÜĞÜ } & 1 & Çok iyi \\
\hline & 2 & İyi \\
\hline & 3 & Yeterli \\
\hline & 4 & Kötü \\
\hline \multirow[t]{4}{*}{ ÇİĞNEME ETKİNLİĞİ } & 1 & Çok iyi \\
\hline & 2 & İyi \\
\hline & 3 & Yeterli \\
\hline & 4 & Kötü \\
\hline $\begin{array}{l}\text { HASTA } \\
\text { DEĞERLENDİRMESİ }\end{array}$ & $1-10$ & \\
\hline
\end{tabular}




\section{ZIRKONYA RESTORASYONLARIN KLINIIK BAŞARISI}

Zirkonyum destekli restorasyonların altyapıları mükemmel dayanım göstermelerine rağmen teknik veya biyolojik problemler ortaya çıkabilmektedir (Sailer I ve ark, 2007) (Beuer F ve ark, 2009). En sık karşılaşılan klinik sorun üst yapı seramiğinin alt yapıdan tabaka halinde (delaminasyon) veya kırılarak ayrılması (chipping) ve altyapının kırılmas1 olarak belirtilmektedir (Sailer I ve ark, 2006) (Raigrodski AJ ve ark, 2012). Alt yapı kırığı köprü restorasyonlarında sık görülen bir komplikasyon olmakla beraber Y-TZP alt yapılı köprü restorasyonlarında görülme sıklığı çok azdır. Yapılan araştırmaların sonuçlarına bakıldığında, zirkonyumun alt yap1 olarak metal ile benzer; diğer seramik sistemlerine göre de daha iyi performans gösterdiği söylenebilir (Silva $\mathrm{N}$ ve ark, 2010).

Sailer I ve arkadaşları posterior bölgedeki zirkonyum restorasyonların 5 ylllı klinik takibini yaptıkları çalışmalarında, \%15.2 oranında üst yapı kırı̆̆1 komplikasyonu gözlemlemişlerdir (Sailer I ve ark, 2007). Zirkonyum restorasyonların üretimi sırasındaki termal genleşme katsayısı faklılıları, alt yapı ve üst yapının arasındaki istenmeyen ısınma ve soğuma oranları, alt yap1 üst yapı arasında oluşan makaslama kuvvetleri gibi faktörler üst yapı kırığının nedenleri arasında gösterilmektedir (AlAmleh B ve ark, 2010) (Stawarczyk B ve ark, 2011). Alt yap1 ve üst yap1 seramiğinin termal genleşme katsayısı uyumlu değil ise, üst yapı seramiğinin firınlama ve soğuma sonrasında iki yapı arasında oluşan sıcaklık farklılıkları, artık stres oluşumuna sebep olmaktadır (Yihong L ve ark, 2010). Oluşan artık stresler ara yüzey özelliğini değiştirerek, zirkonyanın faz değişiminin başlamasına, tanecik büyüklüklerini değiştirerek yüzeyde seramik kırığına sebep olabilmektedir (Denry I ve Kelly JR 2008).

Zirkonyum restorasyonların klinik başarısında, üst yapı hazırlama yöntemleri önemli bir etkiye sahiptir. Üst yap1 hazırlama yöntemleri, üst yapı seramiğinin özelliklerini ve alt yapı-üst yapı sistemini bir bütün olarak etkilediği için üst yapı kırığı komplikasyonu ile ilişkilendirilebilmektedir (Ishibe M ve ark, 2011). Üst yapı hazırlama yöntemlerinden tabakalama tekniğinde, seramik tabakasının eşit ve homojen olarak uygulanmaması seramikte çatlak ve kırıklara neden olabilmektedir. Dental teknisyenin becerisi ve tecrübesi, firınlama sayısı ve süreleri gibi faktörler, tabakalama yönteminin başarısını etkileyebilmektedir (Stawarczyk B ve ark, 2011) (Tsalouchou E ve ark, 2008). Zirkonyum restorasyonlarda karşılaşılabilen üst yapı sorunları, tam konturlu (monolitik) zirkonyum restorasyon yapımı ya da hızlı prototipleme (dosya bölme tekniği, CAD-ONTM) yöntemi ile giderilmeye çalışılmaktadır (Kurıyama $S$ ve ark, 2011). Üst yapı seramiğinin firınlama ve soğuma sıcaklıkları, teknisyen deneyimi gibi faktörler elemine edildiği için konvansiyonel tabakalama ve presleme üst yapı hazırlama yöntemlerinde gözlenebilen termal genleşme katsayıs1 uyumsuzluğundan kaynaklanabilen problemler minumuma inmektedir (Miyazaki T ve ark, 2013). Yapılan çalışmalarda hızlı prototipleme yöntemiyle üretilmiş restorasyonlarda, alt yapı ve üst yapının bağlayıcı tiksotrofik cam seramik materyal ile birleştirilmesinin üst yapı kırığı sorununun gözlenme sıklığını önemli ölçüde azalttığı belirtilmektedir (Kurryama S ve ark, 2011).

Monolitik zirkonyumun, Y-TZP 'nin sertliğinin fazla olması nedeniyle karşıt diş minesini aşındırması merak konusu olmaktadır. Yakın zamanda bu konuyla ilgili yapılan çalışmalarda, cilalanmış parlak zirkonyanın, yaşlandırma simülasyonu yapıldığında dahi, karşıt dentisyonu aşındırmadığı belirtilmektedir (Burgess J ve ark, 2014). Zirkonyanın karşıı diş minesini aşındırmasının engellenmesi için dental laboratuarlarda veya oklüzal uyumlama yaparken ağıziçersindezirkonyum restorasyonlarınçokiyi parlatılması gereklidir. Yakın zamanda karşı diş minesinin aşınması ile ilgili yapılan çalışmalarda, zirkonyum restorasyonlara uygun yüzey bitirmesi işlemleri yapıldığında seramiğe göre daha pürüzsüz (parlak) olduğundan dolayı karşıt dişi seramiklere göre daha az aşındırdığını bulmuşlardır (Jung YS ve ark, 2010).

Zirkonyum restorasyonların klinik başarısını etkileyen önemli faktörlerden biri de restorasyonların simantasyonudur. Zirkonyum restorasyonlar, polikarboksilat ve cam iyonomer gibi geleneksel simanlar ve adeziv resin simanlarla simante edilebilmektedir (O'Brien WJ, 2002). Cam iyonomer simanlar ile zirkonyum restorasyonlarm simantasyonunda çeşitli başarısızlıklar görülebilmektedir. Gargari Mve arkadaşları (2010); zirkonyum restorasyonların simantasyonlarını inceledikleri çalışmalarında zirkonyanın en iyi adeziv simantasyon reçetesinin $0,25 \mathrm{MPa}$ 'lık basınç altında $50 \mu$ 'luk A12O3 ile kumlama ve fosfat içeren monomer 10-metakriloloksidesil-dihidrojenfosfat (MDP) içeren adeziv rezin simanlarlarla simante edilmesi olarak belirtilmiştir (Gargari M ve ark, 2010).

Raigrodski AJ ve arkadaşları (2006), 3 üyeli zirkonyum restorasyonların klinik başarısını inceledikleri çalışmalarında, restorasyonların klinik olarak başarılı performans gösterdiğini, 2. molar diş üst yapı seramiğinde 
küçük kırıkların izlendiğini, üst yapı seramiğinde ayrılma ya da alt yapı kırığı gözlenmediğini belirtmiş̧lerdir (Raigrodski AJ ve ark, 2006).

Soliman MSM ve arkadaşları (2015) farklı CADCAM üretim yöntemlerinin kenar ve internal aralığa etkisini araştırdıkları çalışmalarında, tam kontur restorasyon (Sirona inCoris TZI blocks, Sirona Dental Systems, Bensheim, Almanya) ve zirkonyum alt yap1 (Sirona inCoris TZI blocks) üzerine press-on tekniğiyle üst yapısı hazırlanan iki farklı fabrikasyon yöntemini değerlendirmişlerdir. Tam kontur restorasyonların iç ve kenar uyumlarının, press-on yöntemiyle üst yapısı hazırlanan restorasyonlara göre daha iyi olduğunu belirtmişlerdir (Soliman MSM ve ark, 2015).

Ji MK ve arkadaşları (2015), iki farklı CAD-CAM sistemi ile (Prettau Zirconia ve Zenostar ZR translucent) ve lityum-disilikat cam seramik (IPS e.max press) ile yapılmış restorasyonların kenar aralıklarını inceledikleri çalışmalarında, lityum-disilikat kronların, CAD-CAM anatomik kontur zirkonya sistemine (Prettau Zirconia) göre belirgin bir şekilde daha az kenar aralığına sahip olduğunu bulmuşlardır (Ji MK ve ark,2015).

Kara D ve Yılmaz B (2016)'ın yapmış olduğu çalışmada $\mathrm{CAD} / \mathrm{CAM}$ yöntemiyle hazırlanan monolitik ve çift katmanlı zirkonyum seramik kuronların kenar uyumları ve kırılma dirençleri in vitro olarak değerlendirilmiştir. İki farklı basamak tipinde (shoulder, chamfer) olacak şekilde, prepare edilmiş dişleri, zirkonyum altyapılı seramik kron ve monolitik zirkonyum kron ile restore etmişlerdir. Marjinal uyum açısından en düşük ortalama monolitik shoulder grubunda gözlemlenmiştir $(\mathrm{p}<0.001)$. Kırılma direnci açısından en yüksek değer monolitik zirkonya gruplarına aittir. Bunu sirasiyla zirkonyum altyapılı shoulder ve zirkonyum altyapılı chamfer takip etmiştir $(\mathrm{p}<0.001)$ (Kara D ve Yilmaz B, 2016).

Tan F ve Çömlekoğlu ME (2016)'nun yapmış olduğu çalışmada, translüsent monolitik ve zirkonyum destekli seramik restorasyonların 2 yıllık klinik başarısı değerlendirilmiştir. Çalışmaya posteriorda her iki yarım çenede simetrik 3 üyeli, tek molar gövdeli sabit protetik restorasyon dahil edilmiştir. Tüm zirkonyum restorasyonlar 2 yıllık klinik izlemde, klinik olarak kabul edilebilir başarıda bulunmuştur. Translüsent monolitik ve çift tabakalı restorasyonların klinik performansları arasında anlamlı fark bulunmamıştır. ( $>0.05$ ). Restorasyonların kenar ve iç uyumları karşılaştırıldığında çift tabakalı zirkonyum restorasyonların uyumu anlamlı olarak daha iyi bulunmuştur. $(\mathrm{p}<0.05) \quad$ Restorasyonların premolar dayanağının iç ve kenar uyumu, molar dayanaktan anlamlı olarak daha iyi bulunmuştur $(\mathrm{p}<0.05)$. Restorasyonların karşıt dişi aşındırma ve aşınma değerleri karşılaştırıldı ̆̆ında, translüsent monolitik restorasyonların karşıt dentisyonu anlamlı olarak daha fazla aşındırdığı gözlenmiştir (Tan F ve Çömlekoğlu ME, 2016).

\section{SONUÇ}

1. Günümüzde artan estetik beklenti sonucu zirkonyum destekli ve monolitik zirkonya restorasyonların kullanımı artmaktadır. Monolitik zirkonyumlar biyouyumlulukları, gözeneksiz yapıları, antagonist dişlerde aşınmaya sebep olmamas1, zirkonyum alt yapılı restorasyonlarda karşılaşılan veneer porselende meydana gelen kohesiv kırılmaların olmaması avantajları ile kliniklerde geniş kullanım potansiyeline sahip bir malzemedir.

2. Yapılan in vivo çalışmalar sayesinde hasta ağzında en sağlıklı şekilde kullanılacak malzemeler belirlenebilmektedir. Çalışmalarda mümkün olduğu kadar standart oluşturarak klinik başarı ve başarısızlık nedenleri daha net ortaya konulabilir.

3. Modifiye USPHS klinik değerlendirme kriterleri zirkonya restorasyonların değerlendirlmesi için uygun ve yeterlidir.

4. Monolitik zirkoyumların daha kapsamlı in-vitro ve invivo araştırmalarla incelenmesi malzemenin klinik endikasyonlarına daha fazla ışık tutacaktır.

\section{KAYNAKLAR}

1. Akkayan B, Gülmez T. Resistance to fracture of endodontically treated teeth restored with different post systems. J Prosthet Dent. 2002; 87;431-7.

2. Al-Amleh B, Lyons K, Swain M. Clinical trials in zirconia: a systematic review. J Oral Rehabil. 2010; 37(8):641-52.

3. Anusavice KJ. Quality Evalution of Dental Restorations. Criteria of Placement and Replacement, Chicago: Quintessence Publishing Co,: 1989; 352-400.

4. Batson ER, Cooper LF, Duqum I, Mendonca G. Clinical outcomes of three different crown systems with CAD/CAM technology. J Prosthet Dent. 2014; 112: 770-777.

5. Beier US, Kapferer I, Burtscher D, Dumfahrt H. Clinical performance of porcelain laminate veneers for up to 20 years. Int J Prosthodont. 2012; 25:79-85.

6. Beuer F, Schweiger J, Edelhoff D. Digital dentistry: an overview of recent developments for CAD/CAM generated restorations. J Br Dent. 2008; 204: 505-511. 
7. Bindl A, Mörmann WH. Marginal and internal fit of allceramic $\mathrm{CAD} / \mathrm{CAM}$ crown-coping on chamfer preparations. J Oral. Rehabil. 2005; 32: 441 - 447.

8. Burgess J, Janyavula S, Lawson NC, Lucas TJ, Cakir D. Enamel wear opposing polished and aged zirconia. Oper Dent. 2014; 39(2):189-194.

9. Carranza FA, Newman MG. Clinical Periodontology, 8th Edition. WB Saunders Company,; 1996;564-658.

10. Coelho-De-Souza FH, Camargo JC, Beskow T, Balestrin MD, Klein-Junior CA, Demarco FF.A randomized doubleblind clinical trial of posterior composite restorations with or without bevel: 1-year follow-up. J Appl Oral Sci. 2012; 20(2):174-179.

11. Craig RG, Powers JM. Restorative Dental Materals, 11th Edition. Toronto: Mosby Co,: 2002; 53-65.

12. Curtis AR, Wright AJ, Fleming GJP. The influence of surface modification techniques on the performance of a Y-TZP dental ceramic. J Dent. 2006; 34(3):195-206.

13. Denry I, Kelly JR. State of the art of zirconia for dental applications. Dent Mater. 2008; 24: 299-307.

14. Frese C, Schiller P, Staehle HJ, Wolff D. Recontouring teeth and closing diastemas with direct composite buildups: a 5-year follow-up. J Dent. 2013; 41(11):979-985.

15. Gargari M, Gloria F, Napoli E, Pujia A.M, Zirconia: cementation of prosthetic restorations. Literature review, Oral implantol. 2010; 3(4): 25-29.

16. Hickel R, Peschke A, Tyas M, Mjör I. FDI World Dental Federation: clinical criteria for the evaluation of direct and indirect restorations-update and clinical examples. Clin Oral Invest. 2010; 14:349-366.

17. Ishibe M, Raigrodski AJ, Flinn BD, Chung KH, Spiekerman C, Winter RR. Shear bond strengths of pressed and layered veneering ceramics to high-noble alloy and zirconia cores. J Prosthet Dent. 2011; 105:29-37.

18. Ji MK, Park JH, Park SW, Yun K, Oh GJ, Lim HP. Evaluation of marginal fit of 2 CAD-CAM anatomic contour zirconia crown systems and lithium disilicate glass-ceramic crown. J Adv Prosthodont. 2015;7:271-277.

19. Jung YS, Lee JW, Choi YJ, Ahn JS, Shin SW,Huh JB. A study on the in-vitro wear of the natural tooth structure by opposing zirconia or dental porcelain. J Adv Prosthodont. 2010;2:111115

20. Kara D. Monolitik ve çift katmanlı zirkonya seramik kuronların kenar uyumlarının ve kırılma dirençlerinin in vitro olarak değerlendirilmesi. AMÜ Sağlık Bilimleri Enstitüsü, Uzmanlık Tezi, 2016, Aydın (Danışman: Yard. Doç. Dr. Baykal Y1lmaz)

21. Kelly JR. Dental ceramics: current thinking and trends. Dent Clin North Am. 2004; 48(2):513 - 530.

22. Knoernschild KL, Campbell SD. Periodontal tissue responses after insertion of artificial crowns and fixed partial dentures. J Prosthet Dent. 2000; 84: 492-507.

23. Kuriyama S, Teru1 Y, Higuch 1 D, Goto D, Hotta Y, Manabe A, Takashi Miyazaki. Novel fabrication method for zirconia restorations: Bonding strength of machinable ceramic to zirconia with resin cements, J Dent Mater. 2011; 30(3):419424.
24. Lughi V, Sergo V. Low temperature degradation-aging of zirconia: A critical review of the relevant aspects in dentistry. Dent Mater. 2010; 26(8):807-20

25. Marchack BW, Sato S, Marchack CB, White SN. Complete and partial contour zirconia designs for crowns and fixed dental prostheses: a clinical report. J Prosthet Dent. 2011; 106: 145-152.

26. Marquillier T, Doméjean S, Le Clerc J, Chemla F, Gritsch K, Maurin JC, Millet P, Perard M, Grosgogeat B, Dursun E. The use of FDI criteria in clinical trials on direct dental restorations: A scoping review. J Dent. 2017; 68:1-9.

27. Monaco C, Ferrari M, Caldari M, Baldissara P, Scotti R. Comparison of 2 bonding systems and survival of fiberreinforced composite inlay fixed partial dentures. Int $\mathrm{J}$ Prosthodont. 2006; 19:577-85.

28. O'Brien WJ. Dental Materials and Their Selection, $3 \mathrm{rd}$ ed. Canada, Quintessence, 2002; 132,35-143,46

29. Piconi C, Macauro G. Zirconia as a ceramic biomaterial. Biomaterials. 1999; 20: 1-25.

30. Poggio CE, Dosoli R, Ercoli C. A retrospective analysis of 102 zirconia single crowns with knife-edge margins. J Prosthet Dent. 2012; 107:316-21.

31. Raigrodski AJ, Chiche GJ, Potiket N, Hochstedler JL, Mohamed SE, Billiot S, Mercante DE. The efficacy of posterior three-unit zirconium-oxide-based ceramic fixed partial dental prostheses: A prospective clinical pilot study. J Prosthet Dent. 2006; 96:237-244.

32. Raigrodski AJ, Chiche GJ. The safety and efficacy of anterior ceramic fixed partial dentures: A review of the literature. $J$ Prosthet Dent. 2001; 86: 520-525.

33. Raigrodski AJ, Hillstead MB, Meng GK, Chung KH. Survival and complications of zirconia-based fixed dental prostheses: a systematic review. J Prosthet Dent. 2012; 107:170-177.

34. Raigrodski AJ. Contemporary materials and technologies for all-ceramic fixed partial dentures: a review of the literature. J Prosthet Dent. 2004; 92(6):557-562.

35. Randall RC, Wilson NHF. Clinical testing of restorative materials some historical landmarks. J Dent. 1999;27:54350.

36. Rimondini L, Cerroni L, Carrassi A, Torricelli P. Bacterial colonization of zirconia ceramic surfaces: an in vitro and in vivo study. Int J Oral Maxillofac Implants. 2002; 17: 793798.

37. Sailer I, Bonani T, Brodbeck U, Hämmerle CH. Retrospective clinical study of single-retainer cantilever anterior and posterior glass-ceramic resin-bonded fixed dental prostheses at a mean follow-up of 6 years. Int J Prosthodont. 2013; 26:443-50.

38. Sailer I, Feher A, Filser F, Gauckler LJ, Lüthy H, Hämmerle $\mathrm{CH}$. Five-year clinical results of zirconia frameworks for posterior fixed partial dentures. Int J Prosthodont. 2007; 20(4): 383-8.

39. Sailer I, Feher A, Filser F, Gauckler LJ, Lüthy H, Hämmerle $\mathrm{CH}$. Five-year clinical results of zirconia frameworks for posterior fixed partial dentures. Int J Prosthodont. 2007; 20(4): 383-8. 
40. Sailer I, Feher A, Filser F, Gauckler LJ, Lüthy H, Hammerle $\mathrm{CH}$. Prospective clinical study of zirconia posterior fixed partial dentures: 3 year follow-up. 2006. Quintessence Int 37,685-693.

41. Silva N, Sailer I, Zhang Y, Coelho PG, Guess PC, Zembic A, Kohal RJ. Performance of zirconia for dental healthcare. Materials. 2010; 3:863-896.

42. Soliman, MSM, Mohsen CA, El-Mahallawi O, Abu-Eittah MRH. Effect of Different Cement Spaces on the Vertical Marginal Gap of Full Anatomical Zirconia Bridges. J Am Sci. 2015; 11(6):145-152.

43. Staehle HJ, Wohlrab T, Saure D, Wolff D, Frese C. A 6.5-year clinical follow-up of direct resin composite buildups in the posterior dentition: introduction of a new minimally invasive restorative method. J Dent. 2015; 43(10):1211-1217.

44. Stawarczyk B, Özcan M, Roos M, Trottmann A, Sailer I, Hämmerle CHF. Load-bearing capacity and failure types of anterior zirconia crowns veneered with overpressing and layering techniques. Dent Mater. 2011; 27:1045-1053.

45. Tan F. Bilgisayar ile tasarlanarak üretilen translüsent monolitik zirkonya ve çift tabakalı zirkonya restorasyonların klinik başarılarının değerlendirilmesi. Ege Ü Sağlık Bilimleri
Enstitüsü, Uzmanlık Tezi, 2016, İzmir (Danışman: Doç. Dr. Muherrem Erhan Çömlekoğlu)

46. Triwatana P, Nagaviroj N, Tulapornchai C. Clinical performance and failures of zirconia-based fixed partial dentures: a review literature. $J$ Adv Prosthodont. 2012: 4: 7683.

47. Tsalouchou E, Cattell MJ, Knowles JC, Pittayachawan $\mathrm{P}, \mathrm{McDonald}$ A. Fatigue and fracture properties of yttria partially stabilized zirconia crown systems. Dent Mater. 2008; 24:308-318.

48. Vagkopoulou T, Koutayas SO, Koidis P, Strub JR. Zirconia in dentistry: Part 1. Discovering the nature of an upcoming bioceramic. Eur J Esthet Dent. 2009; 4 :130-151.

49. Yihong L, Hailan F, Yiwang B, Yan Q, Ning X, Zhijian S. Fracture and interfacial delamination origins of bilayer ceramic composites for dental restorations. Journal of the European Ceramic Society. 2010; 30: 1297-1305.

50. Zhang Y, Lee JJ, Srikanth R, Lawn BR. Edge chipping and flexural resistance of monolithic ceramics. Dent Mater. 2013; 29: 1201-1208. 